\title{
First report of Acidovorax avenae subsp. avenae causing bacterial brown stripe disease of rice in Taiwan
}

\author{
Yi-Ru Lai ${ }^{1} \cdot$ Chien-Jui Huang $^{1}$ (D) \\ Received: 24 January 2018 / Accepted: 8 June 2018 / Published online: 18 June 2018 \\ (C) Società Italiana di Patologia Vegetale (S.I.Pa.V.) 2018
}

In October 2016, rice (Oryza sativa L. cv. Tainan-11) leaves with symptoms of brown stripes were firstly observed in Chiayi city, Taiwan. A bacterium was repeatedly isolated on nutrient agar from surface-sterilized symptomatic tissue and did not show fluorescence on King's B plates. Several isolates were purified and maintained on King's B plates. Two isolates, OS01 and OS02, were stored in Luria-Bertani broth with $20 \%$ glycerol at $-80{ }^{\circ} \mathrm{C}$. The rice isolates were phenotypically similar to Acidovorax avenae (Schaad et al. 2008) according to characterization with API 20 NE system (Biomerieux). They were further identified by analysis of $16 \mathrm{~S}$ rDNA and $16 \mathrm{~S}-$ $23 \mathrm{~S}$ rDNA internal transcribed spacer (ITS) regions (Schaad et al. 2008) and multilocus sequence typing (Feng et al. 2009). BLASTn analysis showed that both 16S rDNA and ITS sequences shared $100 \%$ and $>99 \%$ identity to those of $A$. avenae subsp. avenae type strain ATCC 19860 (EU024134 and EU368726). Based on a phylogenetic analysis of the six concatenated genes (gmc, $\operatorname{qgp} B$, pilT, lepA, $\operatorname{trp} B$, and $g l t A$ ), the rice isolates clustered with $A$. avenae subsp. avenae strains (Feng et al. 2009). To fulfill Koch's postulates, leaves of rice cv. Tainan-11 were inoculated with a bacterial suspension according to the method of Schaad et al. (2008). After incubation at $28{ }^{\circ} \mathrm{C}$ for 3 days in closed plastic bags and subsequently for 4 days on a greenhouse bench, the artificially inoculated rice leaves showed brown stripe symptoms indistinguishable from those observed in natural infections. The bacterium which was re-isolated from the

Chien-Jui Huang

chienjui.huang@mail.ncyu.edu.tw

1 Department of Plant Medicine, National Chiayi University, No. 300, Syuefu Rd, Chiayi City 60004, Taiwan, Republic of China symptomatic leaves was confirmed to be A. avenae subsp. avenae by PCR with Aaaf5, Aaaf3/Aaar2 primers (Song et al. 2004). No symptoms developed in the control leaves. To our knowledge, this is the first identification of $A$. avenae subsp. avenae causing brown stripe of rice in Taiwan. The sequences were deposited at GenBank under accession numbers MG818948-MG818949, MG825327MG825328, and MH137619-MH137630.

Acknowledgements This work was financed by the Ministry of Science and Technology (MOST, grant number 106-2311-B-415-001), Taiwan, R.O.C.

\section{Compliance with ethical standards}

Conflict of interest The authors declare that they have no conflict of interest.

Research involving human participants and/or animals The authors declare that no human participants and animals were involved in this study.

Informed consent This manuscript is new and not being considered elsewhere. All authors have approved the submission of this manuscript.

\section{References}

Feng J, Schuenzel EL, Li J, Schaad NW (2009) Multilocus sequence typing reveals two evolutionary lineages of Acidovorax avenae subsp. citrulli. Phytopathology 99:913-920

Schaad NW, Postnikova E, Sechler A, Claflin LE, Vidaver AK, Jones JB, Agarkova I, Ignatov A, Dickstein E, Ramundo BA (2008) Reclassification of subspecies of Acidovorax avenae as A. avenae (Manns 1905) emend., A. cattleyae (Pavarino, 1911) comb. nov., A. citrulli Schaad et al., 1978) comb. nov., and proposal of A. oryzae sp. nov. Syst Appl Microbiol 31: 434-446

Song WY, Kim HM, Hwang CY, Schaad NW (2004) Detection of Acidovorax avenae ssp. avenae in rice seeds using BIO-PCR. J Phytopathol 152:667-676 